\title{
Access to Oral Health Care: A Focus on Dental Caries Treatment Provision in Enugu Nigeria
}

\author{
Nkolika Uguru ( $\nabla$ nkolika.uguru@unn.edu.ng ) \\ https://orcid.org/0000-0002-4643-5160 \\ Obinna Onwujekwe \\ University of Nigeria - Enugu Campus \\ Ogu Ugochukwu Udochukwu \\ University of Nigeria - Enugu Campus \\ Chibuzo Uguru \\ University of Nigeria - Enugu Campus
}

Health Policy Research Group, College of Medicine, University of Nigeria, Enugu campus

\section{Research article}

Keywords: Dental caries, Oral health, caries treatment/services, oral healthcare provision

Posted Date: January 21st, 2020

DOI: https://doi.org/10.21203/rs.2.21374/v1

License: (c) (i) This work is licensed under a Creative Commons Attribution 4.0 International License. Read Full License

Version of Record: A version of this preprint was published at BMC Oral Health on May 19th, 2020. See the published version at https://doi.org/10.1186/s12903-020-01135-1. 


\section{Abstract}

\section{Background}

Dental caries, despite improvement in oral health across the globe, is still a large contributor to the global burden of oral diseases and a major public health concern. In Enugu state Nigeria, there is minimal access to adequate and proper oral health care. This study examined the determinants of dental caries treatment provision and the challenges of providing equitable access to oral health care.

Method

This was a descriptive cross-sectional study conducted in three local government areas in Enugu state Nigeria. The study was conducted using both qualitative and quantitative research methods. The determinants of supply of dental caries treatment services were explored with a focus on provider behaviour, cost of dental services, human resource availability and availability of dental equipment.

\section{Results}

Five factors determine what dental caries treatment service is provided viz: cost of raw materials (100\%), human resources (98.1\%), geographical location (98.1), Government policies (88\%) and price of other goods $(80.8 \%)$. Inadequate awareness and knowledge, high cost of treatment services, inadequately skilled staff, poor government funding and policy for oral health, limited primary healthcare facilities offering dental treatment services and poor knowledge of dental caries treatment options are factors that determine dental service provision and equally influence access to oral health care. There are still a limited number of dental facilities in the country with a growing need for dental caries treatment/services and other dental issues.

\section{Conclusion}

Adequate access to oral health care services is a major concern that affects all aspects of healthcare and a determining factor in the country's drive to achieve universal health coverage. In order to address this, there is a need to incorporate oral health into the general health care system. Dental health facilities need to be strategically located and properly equipped with materials, equipment and adequate skilled staff.

\section{Background}

Access to oral health care is poor in most low and middle-income countries and poor oral hygiene and dental caries have been found to be one of the common causes of school and work absenteeism coupled with poor academic and work performance ${ }^{[1]}$. Efforts made to improve access to oral health care in Nigeria have been largely unsuccessful. Poor integration of oral health into general health has been the bane of the Nigerian health system despite the seeming progress in oral health evidenced by the birth of

the 2012 Oral health policy ${ }^{[2]}$. A study found that the system falls short of many desirable attributes: the system, according to the findings is neither efficient nor effective, available resources in many areas, are 
overstretched and grossly inadequate ${ }^{[3]}$. However, in a bid to improve equitable access to oral health care services, The Nigeria government have included oral health care in the National health insurance scheme [4].

In the majority of Africa, there is little or no access to adequate and proper oral health care ${ }^{[5]}$. The dentist to population ratio in Africa is approximately 1:150,000 which is lower when compared to most industrialized countries at a ratio of 1:2,000 ${ }^{[5]}$. In Nigeria, there are about 4,125 registered dentists, which is about 40,000 people to 1 dentist ${ }^{[5]}$. Wherever dental clinics exist, dental care is unaffordable and expensive for many and therefore restricted to curative services ${ }^{[5]}$. Dental caries, despite improvement in oral health across the globe, still contributes to the global burden of disease and a major public health concern ${ }^{[1]}$. Caries prevalence in Nigeria has been found to vary between $4 \%$ and $40 \%{ }^{[1,6]}$. This is higher in urban than rural area ${ }^{[1,6]}$.

The World Health Organization (WHO) and the World Dental Federation (FDI) in the early '80s, developed a global goal for oral health as a way to promote oral health globally ${ }^{[1]}$. This global goal, has as one of its objectives, that $85 \%$ of a population will have all their teeth in the mouth by the time they are 18 years of age ${ }^{[1]}$. By 2000 , this was still an unrealized dream for most countries ${ }^{[1]}$. In 2012 , three organizations International Dental Federation, International Association of Dental Research and the World Health Organization held an oral health referendum to revisit the global oral health goals ${ }^{[7]}$. A communiqué that focuses on improving global oral health by the year 2020 was issued ${ }^{[8]}$. They proposed that through reducing morbidity and mortality from oral services, promoting evidence-based oral health policies and oral health strengthening, reducing disparities in oral health across population groups and improving access to dental services that improvement in global oral health would be achieved ${ }^{[8]}$. However, this has not been the case in the African region, the reason for this being that the little resources assigned to the health sector are mainly directed towards life-threatening conditions such as HIV/AIDS, tuberculosis, and malaria rather than dental caries and other oral diseases ${ }^{[8]}$.

If the impact of dental caries on economies and different populations around the world are carefully considered, public health decisions concerning the cost of oral health will be a lot more reliable ${ }^{[9]}$. Furthermore, there are many factors that have been known to influence access to dental care and these can be categorized into external and internal factors. The external barriers are inability to obtain dental insurance, shortage and mal-distribution of dentists, the cost associated with dental care, insufficient professional on evidence-based guidelines, lack of inter-disciplinary collaborations and a complex oral health system that can be difficult to navigate ${ }^{[10]}$. The internal barriers are anxiety and fear associated with dental care, low oral health literacy, perceptions and misconceptions that exist about oral health care [10].

Health care resources are scarce, and in the allocation of these scarce resources, decision-makers in Nigeria, pay little or no attention to oral health prevention programs or dental treatment programs ${ }^{[9]}$. Thus in Nigeria, oral health care is seen as insignificant to other aspects of health and is not recognized as 
deserving dedicated attention ${ }^{[2]}$. The country lacks a coordinated system of collecting health data, especially in oral health, thus, making an accurate assessment of the oral health care system difficult ${ }^{[2]}$. There is limited research on access to dental caries treatment service provision in Enugu state. This study will seek to add to knowledge by examining supply determinants of dental caries treatment services in Enugu State.

\section{Methods}

This study was conducted in Enugu State Nigeria. Enugu state is one of the 36 states of the Federal Republic of Nigeria and is divided into 17 Local Government Areas (LGAs). Four urban and thirteen rural LGAs ${ }^{[11]}$. The study was conducted in three local government areas in Enugu State. (Enugu East which is urban with a projected population of 374,100 and Nsukka and Awgu LGAs which are both rural LGAS with projected population of 417,700 and 390,681 respectively) ${ }^{[12]}$.

The state operates a mixed public and private system of healthcare. Public oral healthcare can be accessed at three levels namely primary, secondary and tertiary. At the primary care level, Public dental health facilities offer only primary oral healthcare which is mostly prevention and basic dental services such as scaling and polishing, simple extractions, simple teeth restorations, oral health education and promotion services. The secondary level consists of dental centers, with or without laboratory facilities. Secondary level care includes treatment of more advanced cases of dental diseases and offers more advanced treatment of dental caries and other oral diseases. The cadre of staff employed are mostly general dental practitioners, dental officers, dental therapists, dental nurses and technologists. The third level represents the highest level of oral healthcare and these include the teaching hospitals and specialist hospitals. They offer more specialized and advanced treatment of oral diseases. For the private clinics, they mostly offer both primary and secondary level care with or without laboratories attached.

The setting for this study was based on sites with public health facilities offering primary oral healthcare services and an associated referral hospital. Thus the study was conducted in Obukpa health centre in Nsukka LGA- a primary health centre which accommodates a primary dental centre in the rural site, Federal School of Dental Technology Trans-Ekulu in Enugu East LGA- a dental health facility in the Urban site which offers both primary and secondary oral healthcare and the referral hospital-University of Nigeria Teaching hospital Ituku Ozalla (UNTH) situated in Awgu LGA-which offers mainly tertiary care.

The study was a cross-sectional urban rural study using both quantitative and qualitative research methods. For the quantitative study, a multistage sampling technique was used. Initially, two public dental health care facilities offering primary dental care were randomly selected. One in the urban area and one in the rural area. This was obtained from a State government generated list of public dental health care centers that provide primary oral health services in Enugu State. This list was stratified into urban and rural PHCs and formed the sampling frame for this stage. The referral hospital UNTH, was purposively selected based on the referral pattern of the two primary dental facilities. Private dental facilities situated in both urban and rural LGAs were also selected from a list of all registered private 
facilities obtained from the state ministry of health. This list formed the sampling frame for private health facilities. Two facilities were selected per LGA. At the next stage, all frontline dental service providers in all the selected dental facilities were selected for inclusion in the study. This was done to enable an adequate number of participants take part in the study because of the limited number of dental professionals in the state.

In order to extract qualitative data, in-depth interviews were conducted for all heads of dental facilities and heads of units in facilities included in the study using a structured interview guide. There were 7 respondents in total and saturation was achieved. The in-depth interview of key informants was used to investigate the perception of the dental care professionals on dental caries treatment service provision. It specifically looked at type of service provided, challenges in service provision, influence of government policies and taxes on provision of treatment services, as well as the influence of different health financing mechanisms.

\section{Data Analysis}

The interview guide was pretested and revised before use in study. The interviews were conducted face to face in the dental facilities using audio recorders and later transcribed verbatim. Transcriptions were analyzed using thematic content analysis. Themes were derived based on the access framework adapted from three different authors namely Penchasky and Thomas ${ }^{[13]}$, Levesque and Russell ${ }^{[14]}$ and Saumers [15] as shown in Fig. 1. Relevant themes were derived with a focus on supply based on each dimension of access, the framework was reviewed and revised, quotations and translations were checked and then authors developed an explanatory narrative for this paper.

\section{Results}

The table below shows that majority of the respondents are from public hospitals and they are mainly dentists and dental therapists. Respondents in the public hospitals comprise both tertiary and primary health center staff. The primary health center in the rural area has just one dentist. While the tertiary facility has 35 respondents.

Table 1: Provider characteristics 


\begin{tabular}{|c|c|c|c|c|}
\hline Variables & Total f (\%) & $\begin{array}{l}\text { Public facility } \\
\text { f (\%) }\end{array}$ & $\begin{array}{l}\text { Private facility } \\
f(\%)\end{array}$ & $X^{2}$ (P-value) \\
\hline Geographical location & & & \multirow{4}{*}{$\begin{array}{l}6(11.5) \\
1(1.9)\end{array}$} & \\
\hline Urban & $15(28.8)$ & $9(17.3)$ & & \\
\hline Rural & $37(71.2)$ & $36(67.3)$ & & \\
\hline Total & $52(100.0)$ & $45(86.5)$ & & $12.745(0.001)$ \\
\hline \multicolumn{5}{|l|}{ Facility type } \\
\hline Tertiary Hospital & $35(67.3)$ & $35(67.3)$ & $0(0.0)$ & \\
\hline Rural Health Centre & $1(1.9)$ & $1(1.9)$ & - & \\
\hline Dental clinic & $16(30.8)$ & $9(17.3)$ & $7(13.5)$ & $16.654(0.000)$ \\
\hline Total & $52(100.0)$ & $45(86.5)$ & $7(13.5)$ & \\
\hline \multicolumn{5}{|l|}{ Cadre of Respondents } \\
\hline Doctor & $1(1.9)$ & $1(1.9)$ & $0(0.0)$ & \\
\hline Dentist & $31(59.6)$ & $28(53.8)$ & $3(5.8)$ & \\
\hline Dental nurse & $4(7.7)$ & $3(5.8)$ & 1(1.9) & $1.378(0.711)$ \\
\hline Dental Therapist & 16(30.8) & $13(25.0)$ & $3(5.8)$ & \\
\hline Total & $52(100.0)$ & $45(86.5)$ & $7(13.5)$ & \\
\hline \multicolumn{5}{|l|}{ Highest education level } \\
\hline Diploma & $20(38.5)$ & 16(30.8) & $4(7.7)$ & \\
\hline \multirow[t]{2}{*}{ Bachelor of Dental Surg. } & $26(50.0)$ & $24(46.2)$ & $2(3.8)$ & \\
\hline & $4(7.7)$ & $3(5.8)$ & 1(1.9) & \\
\hline Master's degree & $2(3.8)$ & $2(3.8)$ & $0(0.0)$ & \\
\hline Post-grad. fellowship & $52(100.0)$ & $45(86.5)$ & $7(13.5)$ & $2.245(0.523)$ \\
\hline Total & & & & \\
\hline
\end{tabular}

*Public dental facility in the rural area comprises respondents in both tertiary and primary health facilities

Table 2, shows that the majority of facilities are open Monday to Friday with an average opening time of 8hours. Some private facilities are open till Saturday, but only the tertiary referral center is opened $24 \mathrm{hrs}$, Monday to Sunday. Facility opening days and times differ with the type of facility $(p<0.05)$ 
Table 2. Availability of dental services and provision of treatment 
Variables

$\mathrm{N}=52$
Public

facility

$f(\%)$
Private facility

$f(\%)$

\section{Number of days facility is open to patents}

Monday to Friday

Monday to Saturday

Monday to Sunday (Tertiary)
15(28.8)

$8(15.8)$

28(55.8)
15(28.8) $\quad 0(0.0)$

1(1.9) 7(13.5)

29(55.8) $\quad 0(0.0)$
$\mathrm{X}^{2}$ (P-Value)

44.489(0.000)

\section{Time facility opens}

24hrs (Tertiary)

34(65.4)

34(65.4) $\quad 0(0.0)$

$8 a m-4 p m$

10(19.2)

8(15.4)

2(3.8)

2(3.8)

2(3.8)

$0(0.0)$

9am-5pm

$5(9.6)$

$0(0)$

5(9.6)

Others

1(1.9)

1(1.9)

$0(0.0)$

\section{Dentist always available}

Yes

No (rural)
51(98.1)

1(1.9)
44(84.6)

1(1.9)
7(13.5)

$0(0.0)$
0.159(1.000)

35.324

(0.004)

\section{Services provided by facility}

\section{Dental caries treatment services}

Composite filling

$52(100.0)$

45(86.5)

$7(13.5)$

0.159(0.690)

GIC filling

$52(100.0)$

Amalgam

48(92.3)

45(86.5)

7(13.5)

0.159(0.690)

Extraction

51(98.1)

45(86.5)

3(5.8)

25.757(0.002)

Root canal

51(98.1)

44(84.6)

7(13.5)

0.159(0.690)

Crown

51(100.0)

44(84.6)

7(13.5)

0.159(0.690)

Bridge

$44(84.6) \quad 7(13.5)$

0.159(0.690)

45(86.5)

0.159(0.690) 


\section{Other services}

Scaling and polishing

52(100.0)

45(86.5)

7(13.5)

0.159(0.690)

Oral health education

52(100.0)

45(86.5)

7(13.5)

0.159(0.690)

Emergency oral care

51(98.1)

44(4.6)

7(13.5)

0.159(0.690)

Oral radiography

42(80.8)

44(4.6)

7(13.5)

14.189(0.000)

Dispensing

42(80.8)

40(76.9)

2(3.8)

44.489(0.000)

Laboratory services

44(84.6)

44(84.6)

$0(0.0)$

46.829(0.000)

\section{Provider informs patients of procedure}

Yes

No

51(98.1)

45(86.5)

$6(11.5)$

6.555(0.135)

1(1.9)

$0(0.0)$

1(1.9)

\section{Presence of referral mechanism}

Yes

37(71.2)

30(57.7)

7(13.5)

$3.279(0.070)$

No

15(28.8)

$15(28.8)$

$0(0.0)$

\section{*Where patients are usually}

referred to

Tertiary

Secondary

Private clinic

29(76.3)

1(1.9)

7(21.1)

37(100.0)
22(57.9) 7(18.4)

$1(2.6)$

$8(21.1)$

$31(81.6)$
2.663(0.264)

Total

Table 3 below shows that $78.8 \%$ of the providers from public facilities, stated the availability of both disposable and reusable equipment. A few mentioned only disposable. However, respondents in the private facilities (13.5\%) all used a combination of both disposable and reusable equipment. About $80.8 \%$ of the respondents across facility types stated that they follow national guidelines for infection prevention. A good number of respondents from both facility types indicated that they have functional equipment. All respondents from the private health facilities surveyed and interviewed indicated availability of clean water, soap, glove, mask and disposable syringe compared to public.

Table 3 Comparing available equipment and infection control measures in public and private dental facilities 


\begin{tabular}{|c|c|c|c|c|}
\hline \multirow[t]{2}{*}{ Variables } & \multirow{2}{*}{$\begin{array}{l}\text { Total } n \\
\text { (\%) } \\
\mathrm{N}=52\end{array}$} & \multirow{2}{*}{$\begin{array}{l}\text { Public } \\
\text { facility } \\
\mathrm{n}(\%)\end{array}$} & \multirow[t]{2}{*}{$\begin{array}{l}\text { Private facility } \\
\mathrm{n}(\%)\end{array}$} & \multirow[t]{2}{*}{$X^{2}$ (P-value) } \\
\hline & & & & \\
\hline \multicolumn{5}{|l|}{ Equipment used in facilities } \\
\hline Disposable & $6(11.5)$ & $6(11.5)$ & $0(0.0)$ & $1.055(0.580)$ \\
\hline Reusable & $2(3.8)$ & $2(3.8)$ & $0(0.0)$ & $0.324(0.569)$ \\
\hline Auto-disable & 1(1.9) & $1(1.9)$ & $0(0.0)$ & $0.159(1.000)$ \\
\hline Both Disposable and Reusable & $48(92.3)$ & $41(78.8)$ & $7(13.5)$ & $0.674(1.000)$ \\
\hline \multicolumn{5}{|c|}{$\begin{array}{l}\text { Usage of national guideline for infection } \\
\text { prevention }\end{array}$} \\
\hline \multicolumn{5}{|l|}{ Yes } \\
\hline No & $1(10)$ & $1(10)$ & $1(10)$ & $70501010)$ \\
\hline Can't say & $9(17.3)$ & $8(15.4)$ & $0(0.0)$ & $1.000(0.049)$ \\
\hline \multicolumn{5}{|l|}{$\begin{array}{l}\text { Available functional equipment in } \\
\text { facilities }\end{array}$} \\
\hline \multicolumn{5}{|l|}{ Electric autoclave } \\
\hline \multirow{2}{*}{ Electric heater sterilizer } & $51(98.1)$ & $44(04.0)$ & (13.5) & $0.159(1.000)$ \\
\hline & $38(73.1)$ & $31(59.6)$ & $7(13.5)$ & $2.980(0.169)$ \\
\hline Fun health sterilizer & $36(69.2)$ & $29(55.8)$ & $7(13.5)$ & $3.595(0.085)$ \\
\hline Electric steamer & 18(32.7) & 18(34.6) & $0(0.0)$ & $4.282(0.039)$ \\
\hline Pot with cover & $14(25.0)$ & 12(23.1) & $2(3.8)$ & $0.011(0.916)$ \\
\hline Cold sterilization & $34(65.4)$ & $28(53.8)$ & $6(11.5)$ & $1.477(0.399)$ \\
\hline X-ray machine & $43(82.7)$ & $39(75.0)$ & $4(7.7)$ & $3.689(0.055)$ \\
\hline Dental syringe & $52(100.0$ & $45(86.5)$ & $7(13.5)$ & $0.161(1.021)$ \\
\hline Light curing machine & $46(84.6)$ & $39(75.0)$ & $7(13.5)$ & $1.055(0.580)$ \\
\hline \multicolumn{5}{|c|}{$\begin{array}{l}\text { Available and functional resources for } \\
\text { infection control }\end{array}$} \\
\hline \multicolumn{5}{|l|}{ Clean water } \\
\hline \multicolumn{5}{|l|}{ PPE } \\
\hline \multirow[t]{2}{*}{ Soap } & 51(08 1) & $14(816)$ & $7(135)$ & $0159(0,690)$ \\
\hline & $52(100.0)$ & $45(86.5)$ & $7(13.5)$ & $0.234(0.873)$ \\
\hline
\end{tabular}


Table 4 below shows the cost of dental caries treatment procedure per patient. For a complete procedure, the average amount charged for consultation per patient is N1357 and N1580 in public and private facilities respectively. The average cost for the majority of procedures is much higher in private facilities.

The data shows that the Levene's test for registration, $x$-ray, composite filling, GIC filling, scaling and polishing, porcelain crown, acrylic crown and bridge for both facilities are higher than 0.05 so we conclude that the variability in price between the two groups is almost the same. T-test results for consultation, composite and GIC fillings, extraction, root canal and scaling and polishing show a $p<0.05$, we, therefore, reject the null and accept the alternative hypothesis $\left(H_{1}\right)$ which states there is a significant difference in the amount charged per complete procedure in the public and private dental facilities. For the other procedures, $p>0.05$, we, therefore, accept the null hypothesis $\left(H_{0}\right)$ that there is no significant difference in the amount charged per complete procedure in the public and private dental facilities.

Table 4 Cost of dental caries treatment procedures per patient 


\begin{tabular}{|llllll|}
\hline Variables & $\begin{array}{l}\text { Public facilities } \\
\text { Mean (SD) }\end{array}$ & Private facilities & $\begin{array}{l}\text { Levene's } \\
\text { test for } \\
\text { equality } \\
\text { of } \\
\text { variances }\end{array}$ & $\begin{array}{l}\text { t-test for } \\
\text { equality } \\
\text { of } \\
\text { means } \\
\text { (sig-2 } \\
\text { tailed) }\end{array}$ & Total Mean (SD) \\
\hline Registration & $1357.1(801.8)$ & $1580.7(648.5)$ & 0.122 & 0.090 & $1550.0(667.0)$ \\
\hline Consultation & $571.4(534.5)$ & $1113.6(644.9)$ & 0.770 & 0.007 & $1039.2(653.8)$ \\
\hline Drug & $11.4(75.4)$ & $571.4(534.5)$ & 0.000 & 0.012 & $88.23(277.6)$ \\
\hline X-ray & $976.7(552.5)$ & $1142.8(556.3)$ & 0.000 & 0.311 & $1000.0(247.4)$ \\
\hline $\begin{array}{l}\text { Composite } \\
\text { filling }\end{array}$ & 6045.5(1033) & $9714.3(955.9)$ & 0.725 & 0.000 & $6549.0(1616.3)$ \\
\hline GIC filling & $5090.9(1654)$ & $16714.3(1592.9)$ & 0.580 & 0.000 & $6686.3(7007.1)$ \\
\hline $\begin{array}{l}\text { Amalgam } \\
\text { filling }\end{array}$ & $4193.2(947.6)$ & $5333.3(877.4)$ & 0.000 & 0.000 & $4265.9(966.0)$ \\
\hline Extraction & $4340.9(491.5)$ & $7857.1(367.6)$ & 0.657 & 0.000 & $4823.5(1599.4)$ \\
\hline Root canal & $19545.5(3015)$ & $31214.3(596.1)$ & 0.432 & 0.000 & $21147.1(6221.2)$ \\
\hline $\begin{array}{l}\text { Porcelain } \\
\text { Crown }\end{array}$ & $34932(2002.4)$ & $40500.0(2161.4)$ & 0.154 & 0.513 & $35600.0(12182.3)$ \\
\hline Acrylic crown & $11714.3(5964)$ & $13238.6(4796.4)$ & 0.350 & 0.077 & $13029.4(4116.3)$ \\
\hline $\begin{array}{l}\text { Bridge (Fixed) } \\
\text { Partial }\end{array}$ & $11486.1(8392)$ & $29166.7(14288.7)$ & 0.058 & 0.944 & $75307.7(74713.2)$ \\
\hline $\begin{array}{l}\text { Scaling and } \\
\text { polishing }\end{array}$ & $1666.7(1813)$ & $6714.3(3309.5)$ & 0.828 & 0.023 & $3526.3(3802.3)$ \\
\hline
\end{tabular}

Figure 2 shows factors which influence the provision of dental caries treatment services in either public or private facilities: Cost of raw materials (100\%) affects the cost of providing more and suitable equipment affects it the least (70\%)

\section{Findings of qualitative interviews stated below show:}

Dental caries treatment mostly provided: Majority of the respondents stated that tooth extraction is the most common service provided in their facilities. Most of the respondents come so late with untreated dental caries that the only options left are root canal and extraction. Because extraction is the cheapest option, they usually opt for it. However, some dentists also claim that a good percentage of patients 
receive dental filling. Root canal therapy, crowns and dentures which are treatment options for dental caries. Some respondents also stated that some patients come in requesting for dental fillings, however, because most present late, they are required to do root canal treatment however when the cost of root canal treatment is revealed they opt out for extraction.

"Extraction is the one that is regular. The patients may not be able to afford to pay for other ones, they will go for extraction. It is the cheapest". (P1, $P 2, P 3)$ We usually provide fillings and root canal therapy for bad cases but sometimes the patients cannot afford to pay despite our insistence so we might end up doing more extractions (P4)

"Most of them cannot pay because of their economic status. Most patients will always want to go for root canal but by the time you tell them how much root canal costs, they will end up telling you "I don't have that kind of money" please remove the tooth. Very few of them go straight and ask for tooth extraction. $(P 3, P 6)$

Factors influencing provision of services: All the respondents state that the equipment and technological advances affect the type of treatment provided and also influences the pricing of services. The availability of electrical power source is a crucial issue in service provision because dental procedures need electricity it is difficult to provide services without adequate power supply. Majority of the respondents claim that the epileptic power supply has necessitated a rise in the cost of services to accommodate this. Only the public hospitals claim that their pricing remains the same even when there is no power.

"... One of the major challenges we have is power supply. Most times we have to provide a generator. If there is no power, we use our generator and then continue treatment. But of course that will now increase the cost of treatment because we now spend more providing power that government should be giving us." (P1)

Most providers have an alternate power source which drives up cost. Respondents also claim that the type of equipment available in the facility will affect the ability to provide diverse treatment options for dental caries. Respondents in the rural public primary care facility are particularly affected by lack of equipment as most rural primary care facilities are grossly under equipped

"Of course type of equipment available affects cost of services. Like fillings we can't do complex dental fillings. We do very simple fillings because the type of equipment that we have affects it. We don't have amalgamator for preparing our amalgams, we don't have filling equipment so it affects. We should do simple filling here as primary rural health care. We don't have them, we don't have hand pieces for cutting, and we don't have bowls. So most time we just do GIC fillings or atraumatic restorative treatment which does not require us to use machines"( $P 7)$

Some other providers complained about the fluctuating or inordinate cost of dental materials affecting cost of treatment. Dental service provision in most cases seems to be a monopoly in Enugu State and as 
such price fixing by individual private dental practitioners is rampant. The dental facility heads set prices based on how cheap or expensive they purchased the consumable dental materials and what they perceive their profit margin should be.

Cost of treatment is determined by cost of materials but this is not immediate unless the management sees no returns" (P6). I usually charge based on cost of material. I can be lenient at times but if I see no returns I have to increase charges a bit so I can buy more materials. $(P 5, P 4, P 6)$

Government policies and taxes have also affected the cost of dental caries treatment services as well as every other dental service. Majority of the respondents state that the since most of the equipment and consumables used in dental caries treatment are not manufactured locally, any increase in government tariff or importation ban, will drive the cost of equipment and products up and this will affect the pricing of services. However, this view was expressed mainly by the respondents in the private dental facilities.

"Is just all these tariffs they place on importation. You know all the materials are almost imported. So when the price increase you are bound to increase your own treatment course so we do not increase on our own but based on cost of materials".(P2)

Let's say it has affected negatively definitely because we have multiple taxation in Enugu State. Local government will tax you, state government will tax you, and environmental agency will tax you. All these things from one establishment and all these are still going back to government purse. So that multiple taxation is not encouraging. When you check how much you pay in a year plus the facility equipment and all those stuff. It is not easy and of course the patient has to bear all these costs. $(P 3, P 4)$

Awareness: Most of the respondents believed that the majority of members of their community had little knowledge about dental caries treatment options and treatment of dental diseases as a whole. This they believe would account for late presentation of most patients with dental caries which would have progressed so bad that the only option would be to do a root canal or extraction. As root canal is more expensive, a lot of them opt out for extraction

"Ok the challenges I face is that most of the community members are not enlightened that is they are ignorant of dental care... (P7)

Location: Some respondents stated that facility location generally influence the type of services provided, the number of patients seen in a facility and the type of patients seen. While some others, (mostly respondents in the private dental facilities) opined that location will only influence the caliber of patients that attend a dental facility and not the type of services provided. However provision of a type of service is most times tailored to the ability to pay which is a reflection on the type of patient attending.

"We don't get a large number of patients because the facility is far from town. When you add the transport cost with treatment cost and inconvenience of travelling to the teaching hospital, a lot of patients opt out for clinics in town. (P6) 
"Because of my location, respondents in the high socio-economic strata don't like coming to my clinic. So that is when I refer them to other dentists with dental clinics situated in upper class neighborhoods (P3)

There is no uniform pricing for dental caries treatment services among dental facilities in both public and private facilities. Even in private facilities prices sometimes vary because some respondents cost services provided in their facilities based on location.

"My price is partially based on location and is not about the price of the materials. We all buy dental materials from the same market so I feel the cost of my services is based more on location and my target clientele. My target market is not very rich because if they are rich I can adjust my prices at any time".

Staff number and mix: The right number of staff and appropriate staff mix goes a long way in improving service provision in healthcare services ${ }^{[16]}$. Majority of the respondents claim to have an appropriate number of staff, with the right staff cadre to provide quality dental care. We observed that the public facilities had a good complement of staff except for the primary care facility in the rural area. This had only one dentist catering to the population. The private facilities claimed to each have different staff cadres in their dental team making service provision better. However on further probing we observed that the private clinics most times had one staff cadre performing multiple functions such as a dental therapist doubling as a dental surgery assistant. The human resource challenge in public dental facilities offering primary dental care in the rural areas is glaring however this challenge also exists in the private facilities though muted.

"Another thing I face is that you know they said two good heads is better than one so I'm all alone here. If I need a second opinion I don't have anybody to turn to. So that is another challenge I'm facing. Besides the work is too much for one person. But because I am alone and greatly short staffed. I don't really take on too many patients and I don't think the services provided here will ever meet the needs of the people unless the situation changes" (P7)

My staff strength is adequate I have two dental therapists and one doubles as a dental nurse and I have part time technologists. (P3, P4)

We have enough doctors and dental staff to meet the needs of our patients. We have the full complement. All staff cadres are ably represented. (P6)

Patients that present at the dental clinic mostly pay out of pocket and only a few of the facilities offer health insurance for clients. Namely the tertiary institution, and a few private dental facilities in the urban area. The majority of dental health facilities do not cater to patients on health insurance. Dental treatment services under the National Health Insurance Scheme (NHIS) is listed as secondary care and as such dental health care providers are secondary care providers. Most dentists frown at this because it means the patients do not have immediate access to the dental health care provider and as such most 
patients turn up late. Other respondents opined that many dental health care providers and even patients have very poor knowledge of how the insurance scheme works for dentistry.

"Well to be frank with us, NHIS has not really tried in the dental aspect. The most covered treatment choice is extraction. If a patient opts out of an extraction, then any other treatment becomes too expensive. The cheapest any practitioner would want to do a root canal treatment is twenty thousand $(20,000)$. NHIS don't cover it and so that means they are encouraging patients to remove their teeth. So treatment option for anybody that is under NHIS is either scaling and polishing or extraction (P3, P4). There are other insurance types, mainly private health insurance which is better but not available to everyone (P3).

'We have NHIS but to be honest most patients still end up paying out of pocket, because the NHIS plan does not cover most of the treatment needed and even when they cover, the process is so tedious that some patients just opt to pay" $(P 6)$

$":$ More awareness is needed and the insurance agencies should review their level of operation and then the population should stop being scared because most of them have this phobia for dental treatment and anything dental. No dentist can go to people's houses to force them out. So I think information is the key actually and then government also should review their own aspect and open more windows. (P3, P4, P5)

Respondents opined also that the social health insurance scheme benefit package is very poor and policies regarding dental health insurance are basically non-existent or very poorly formulated as there is minimal awareness or knowledge about dental health insurance amongst HMO's and policymakers. This is reflected in the poor benefits package and the inability of most HMO's to include dentistry in their health insurance plans. Only a few HMO's have relatively robust benefits packages and they are mainly private health insurance plans.

"Well to be frank with you when it comes to dental policies most of my friends that are into health insurance and all what not that are doctors don't really know anything about dental treatment and its policies. They usually more interested in medical insurance. I keep telling them that dental aspect is very important. They provide little or nothing and if you check very well those people that made the health financing policies are not even dentist" (P2, P3).

"Yes. At the policy level dentistry is important. In fact at the policy level it is very important because when you make things better, now so many people are going for the NHIS medically because they are seeing the benefit but most of them are not going in dental because they don't see any benefit. Is either I wash my teeth or I remove it." (P2, P3, P4)

On the issue of fee exemptions and subsidies, most respondents are not aware of any government policy directive on this and usually only give discounts on compassionate grounds. Each facility grants indigent clients discounts based on their assessment of poverty status. There is no scientific way of deciphering this. Neither is there any laid down protocol for this. Waiver or subsidization of fees is dependent on the 
dentist and the management of the facility. Some practitioners, especially in the private sector, usually give the clients a payment plan where they can pay their fees in smaller regular instalments,

"Most times I do that out of empathy not that there is a discount constitution. So my giving an exemption or price waiver depends on my interaction with the patient and if I can help" (P3).

"There is nothing like fee exemption or subsidy and I don't think there is anything in the government policy that says that. If there is I have not seen" We just give discount for some people period. Maybe the government hospital can give full waiver but how can private do that? We are struggling too in this harsh economy (P4).

In a public center, you do not have the power to give any waiver or subsidy unless it's an already documented protocol in the center. If not permission must be sought and the go-ahead given by management before that can be done ' $(P 6, P 7)$

\section{Discussion}

There are many factors that influence the ability to access dental care. These factors form a multidimensional matrix in which many barriers may occur quite simultaneously ${ }^{[10]}$. The barriers to accessing dental care are the prohibitive costs associated with dental care, inability to obtain dental insurance, shortage and mal-distribution of dentists, insufficient number of dental health facilities and oral health care system that is complex and difficult to navigate amongst others ${ }^{[10]}$. The current study sought to assess the factors influencing dental caries treatment service provision, primarily, as a way to assess access to oral health care.

There is a dearth of dental facilities and a limited number of dentists in Enugu when compared with the number of persons in need of oral care. The large population and the number of dental clinics that exists is inadequate to meet the needs of the populace. Olusile et al posited that every local government should have a functional dental clinic to adequately meet the needs of the larger rural population ${ }^{[17]}$. Despite this recommendation, this anomaly in distribution of dental facilities in LGAs still exist. For instance, this study shows that within Nsukka environs (rural LGA in the study), there are about four dental facilities (1 public and 3 private) and one dental laboratory. With a population of 417,700 , this is very inadequate and cannot meet the needs of the population. This is possibly the only rural primary dental facility in a state with 17 LGAs. This is unlike general health facilities which abound in every local government area.

The availability of dental equipment and materials are quite necessary for the delivery of oral care ${ }^{[18]}$. Availability of equipment or lack of it can influence what services are provided by a facility. Lack of equipment can hamper the treatment options for patients. A dental facility that only has equipment for extraction, will not be able to proffer options to the patient. This in a way, also will affect

access/utilization. A study in eastern Africa ${ }^{[19,20]}$ found that less than half of the facilities didn't have the necessary materials consistently, and thus were unable to provide services required even if demanded by 
dental patients. This is collaborated by this current study, which shows the inability of one of the respondents to provide a dental caries treatment option due to lack of equipment. The provide was unable to provide appropriate treatment and opted for an alternative that would suit the equipment available. Thus poor equipping of dental facilities across facilities would ultimately deride the basis for quality and equitable oral health care which is one of the positive throwbacks of universal health coverage. Dental caries treatment services cannot be provided in a facility if the proper equipment and staff are unavailable. One of the possible reasons for this unavailability could also be the cost of procurement and maintenance of requisite equipment.

Demand usually influences the supply and where there is demand, supply becomes imminent ${ }^{[2]}$. Cost of services is a vital determinant to access ${ }^{[18,20]}$. In our study, we observed that the majority of the dental caries treatment services provided were influenced by the demand of the consumers. This demand is usually tied to the cost of services. Cost of services is highest in private dental facility as against public facilities. One of the possible reason for this is that the private provider bears the whole cost of financing the dental clinic without any input from government and in a situation where the private facilities use alternate power supply to augment or replace entirely power from the national grid, the cost of running dental treatment services with alternate power source like generator is usually incorporated into their service charge. In comparison, governments make large financial input into public dental facilities and so dental caries treatment services are provided to the public at subsidized rates, therefore making dental care cheaper in public facilities ${ }^{[2]}$.

Some of the facilities used for this study are NHIS accredited and also have private health insurance clients although we observed that the majority of the facilities do not operate any form of health insurance. The NHIS is expected to provide additional funding for oral healthcare ${ }^{[9]}$ however because dental care is not under primary healthcare, dental clinics do not benefit from capitation. This nonfunding of dental clinics by the scheme coupled with patient unreliability and HMO payment unreliability could also be a reason why the majority of the private dental clinics do not register as National health insurance providers. Another reason could be that the dental health benefits package under NHIS is so minimal that a lot of procedures that could be covered for dental caries treatment are not. All these will definitely affect the equitable provision of dental caries treatment services and inevitable reduce access for the low-income population groups. This observation is similar to that found in other studies ${ }^{[10]}$.

In some cases, prices are also slashed based on the clients' ability to pay. This is, however, the choice of the dental practitioner and not a written policy. Although cost is subsidized in some facilities (in some cases through this scheme and in other cases a personal choice or the medical director), however, because the main method of financing oral health is out-of-pocket payments, there remains limited financial access to oral care ${ }^{[2]}$. Another cost barrier is that there is usually a fluctuation in the tariff placed on importation. When the tariff placed on the importation of any of the equipment or materials increases, so does the cost for the services rendered with it. This affects most private facilities. 
Cost of services is a major hindrance to accessing oral care because a greater part of the population that still live below minimum wage, are in need of dental services. Dental facilities (public and private) in the country have been increasing in number, extending dental services to areas that were previously underserved ${ }^{[20]}$. However, equipment and materials required for the provision of oral health care are expensive to procure and the technical support for the maintenance of these, are not readily available or easily accessible. Cost of raw materials in the current study is one of the factors that determine the provision of any dental caries treatment service. The cost of raw materials could either delay the acquisition of such material therefore in effect hinder service provision or if purchased at a high cost, will affect service charge which could in effect reduce or hinder access to such services.

The number and skill mix of dental professionals as well as the physical presence of a dentist in the dental facilities is very important to dental care delivery and as such facilities that do not have a requisite number of dental care professionals with a dentist available always, are unable to provide optimal service. In our study we observed that the public facility in the rural area has only one dentist who might not be available always, this will inadvertently disturb service provision. On the other hand, the private facilities also have only one dentist, however, most of them have a good complement of staff on paper and as such patient can be attended to or referred appropriately. However the observation minimal staff doing multiple functions is a mainstay. This will still compromise quality of service but will enable practice owners cut down expenditure.

The issue of skill mix also affects service provision if there are inadequately trained staff to manage dental equipment. For example, if equipment is available and there are no staff or trained staff to man it, provision of service remains a problem. There is inadequate financial and human capacity to provide and manage oral health services. Some of the facilities in the current study are either not adequately staffed or lack proper skills mix of staff to provide the required services. As corroborated by another study, it was observed that the ability of practitioners to perform clinical procedures is an important determinant of the kind of treatment offered ${ }^{[18]}$.

Geographical location was also found to determine the provision of services. This substantiates findings from a studywhich posited that oral health services are not readily accessible to the majority of the

population in terms of geographical location ${ }^{[2]}$. However, some facilities located mostly in the rural areas, do not possess most of the equipment needed for dental treatment because of the rural nature of the area, the inadequate light source to operate machinery and possibly non-availability of adequate security for dental equipment.

\section{Conclusion}

Access to oral care is a major concern that affects all aspects of healthcare. Inadequate awareness, knowledge, cost, inadequately skilled staff, limited facilities and treatment options are factors that determine dental service provision and equally influence access to oral health care. There is still a limited number of dental facilities in the country providing optimal and equitable dental care services. In order to 
address this, the discourse of general health is incomplete without oral health. There is a need to integrate oral healthcare into the general health care system. Dental health facilities need to be properly equipped with materials, equipment and appropriate skills mix of trained dental staff. There is also a need to encourage public private partnership with regards to oral healthcare. This is in order to drive down excessive costs and reduce individual price setting by practice owners. A public private partnership environment will also help regulate procedure prices and provide a means of offering financial aid to practices ensuring quality service.

As has been stated earlier, oral health is yet to be taken seriously and incorporated as part of general health in Nigeria. Rather, what has been practised is the existence of small dental units within the main general hospital complex ${ }^{[19]}$. However, in recent times, medical researchers have realized the nature of the relationship existing between poor oral health and general health care and are advocating for integration to achieve universal health coverage for all. ${ }^{[19]}$.

\section{Declarations}

\section{Ethics approval and consent to participate}

Ethical clearance for this study was obtained from the Ethical review board of the University of Nigeria Teaching Hospital Enugu. Written and verbal consent (captured in the tape recorder) was obtained from the respondents. The reason for the verbal consent was because some of the respondents preferred given consent verbally to signed written consent. The ethic committee approved this procedure.

\section{Availability of data and materials}

All dataset used or analyzed during the current study, are available from corresponding author on reasonable request.

\section{Competing interests}

The authors declare that they have no competing interests.

\section{Funding}

The study was personally funded by the principal investigator.

\section{Author Contributions}

UN conceptualized the study, conducted the research and wrote the manuscript. 00 contributed to study concept, participated in the development of methodology and writing and peer review of the final manuscript. UO participated in data collection and writing of the final manuscript. UC participated in writing and peer review of the manuscript. all authors have read and approved the manuscript

\section{Acknowledgement}


Not applicable.

\section{References}

1. Braimoh, BO, Umanah, AU \& llochonwu, NA. Caries Distribution, Prevalence, and Treatment Needs among12-15-Year-Old Secondary School Students in Port Harcourt, Rivers State, Nigeria. Journal of Dental Surgery, 2014;1-6. http://dx.doi.org/10.1155/2014/483760

2. Adeniyi AA, Sofola OO, Kalliecharan RV. An appraisal of the oral health system in Nigeria. Int Dent J. 2012;62(6): 292-300. doi: 10.1111/j.1875-595X.2012.00122.x

3. Uguru, N., Uzochukwu, B., Uguru, C., Onwujekwe, O. Determinants and inequalities in the utilization of routine oral health care services in SouthEast, Nigeria. Journal of Dental and Medical Sciences. 2016;15: 14

4. Federal Ministry of Health Nigeria. National Oral health policy. 2012. Retrieved from: health.gov.ng/doc/ORALHEALTHPOLICY.pdf.

5. Yes, poor oral hygiene has a huge impact on Africa, this is how... 2017. Retrieved from: www.cnbcafrica.com/zdnl-mc/2017/04/13/oral-hygiene-impact-africa/

6. Omitola, OG \& Arigbede, AO. Prevalence of dental caries among adult patients attending a tertiary dental institution in South-South region of Nigeria, Port Harcourt Medical Journal, 2011;6(1):52-58.

7. FDI World Federation. FDI white paper. Oral health worldwide. 2012 https://www.fdiworlddental.org/fdi-news/number-25-november-2012. Accessed June 52016

8. FDI World Federation. The Challenge of Oral Disease - A call for global action. The Oral Health Atlas. 2nd ed. Geneva: FDI World Dental Federation. 2015 Available from: fdiworldental.org/oral-healthatlas. Accessed 5/6/16

9. Fraihat, N., Madae'en, S., Bencze, Z., Herczeg, A \& Varga, O. Clinical Effectiveness and CostEffectiveness of Oral-Health Promotion in Dental Caries Prevention among Children: Systematic Review and Meta-Analysis. International Journal of Environment Research and Public Health. 2019;16(2668): 1-33; doi:10.3390/ijerph16152668

10. Bersell, C. Access to Oral Health Care: A National Crisis and Call for Reform. The Journal of Dental Hygiene 2017; 91:1:6-14

11. Enugu State Government. Wikipedia contributors. (2018, October 2). Enugu State. In Wikipedia, The Free Encyclopedia. Retrieved 17:35, October 14, 2018, from https://en.wikipedia.org/wiki/Enugu_State 
12. Brinkoff, T. (2017, November 7). Africa. Population of Enugu state Nigeria. Retrieved October 10, 2018, from https://www.citypopulation.de/php/nigeria-admin.php?adm1 id=NGA014

13. Penchansky, R., Thomas, J.W. The concept of access: definition and relationship to consumer satisfaction. Med Care. 1981; 9(2):127-40

14. Levesque, J., Harris, M. and Russell, G. Patient-centered access to health care: Conceptualizing access at the interface of health systems and populations. International Journal for Equity in Health. 2013; $12-18$

15. Saurman, E. (2016). Improving access: Modifying Penchansky and Thomas's Theory of Access. Journal of Health Services Research and Policy. 21(1) 36-39. DOI: 10.1177/1355819615600001

16. Ogunbodede, E.O., Kida, I.A., Madjapa, H.S., Amedari, M., Ehizele, A., Mutave, R., Sodipo, B., Temilola, S., Okoye, L. (2015). Oral Health Inequalities between Rural and Urban Populations of the African and Middle East Region. Adv Dent Res. 27(1):18-25. doi: 10.1177/0022034515575538.

17. Olusile A O. Improving low awareness and inadequate access to oral health care in Nigeria: The role of dentists, the government \& non-governmental agencies. Niger Med J 2010;51:134-6

18. Nyamuryekung'e KK. Lahti, SM \& Tuominen, RJ. The relative patient costs and availability of dental services, materials and equipment in public oral care facilities in Tanzania. BMC Oral Health, 2015;15(74): DOI 10.1186/s12903-015-0061-3.

19. Khalifa N, Allen PF, Abu-bakr NH, Abdel-Rahman ME, Abdelghafar KO. A survey of oral health in a Sudanese population. BMC Oral Health. 2012;12:5-6831-12-5.

20. Federal Ministry of Health. A report of the Technical Working Group for the Development of a Road Map for the Improvement of Oral Health in Nigeria. 2011. Abuja: FMoH.

\section{Figures}




\begin{tabular}{|c|c|c|}
\hline $\begin{array}{l}\text { Dimension of } \\
\text { access }\end{array}$ & Definition & Dimension components \\
\hline Accessibility & $\begin{array}{l}\text { Location of health } \\
\text { services }\end{array}$ & $\begin{array}{l}\text { An accessible service is within reasonable proximity to } \\
\text { the consumer in terms of time and distance }\end{array}$ \\
\hline Availability & Supply of services & $\begin{array}{l}\text { An available service has sufficient services and } \\
\text { resources to meet the volume and needs of the } \\
\text { consumers and communities served. }\end{array}$ \\
\hline Affordability & $\begin{array}{l}\text { Ability of consumers } \\
\text { to pay }\end{array}$ & $\begin{array}{l}\text { Affordable services examine the direct costs for both } \\
\text { the service provider and the consumer. }\end{array}$ \\
\hline Acceptability & $\begin{array}{l}\text { Consumers } \\
\text { perception of health } \\
\text { service }\end{array}$ & $\begin{array}{l}\text { An acceptable service responds to the attitude of the } \\
\text { provider }\end{array}$ \\
\hline Accommodation & Organization & $\begin{array}{l}\text { An adequate service is well organized to accept clients, } \\
\text { and clients are able to use the services. Considerations } \\
\text { of adequacy include hours of operation (after-hour } \\
\text { services), referral or appointment systems, and facility } \\
\text { structures (wheelchair access). }\end{array}$ \\
\hline Awareness & $\begin{array}{l}\text { Communication and } \\
\text { Information }\end{array}$ & $\begin{array}{l}\text { A service maintains awareness through effective } \\
\text { communication and information strategies with relevant } \\
\text { users (clinicians, patients, the broader community), } \\
\text { including consideration of context and health literacy. }\end{array}$ \\
\hline
\end{tabular}

Adapted from (Saumers, 2016): Access framework

\section{Figure 1}

Framework for analyzing supply of dental caries treatment services 


\section{Factors that determine provision of dental caries treatment services}

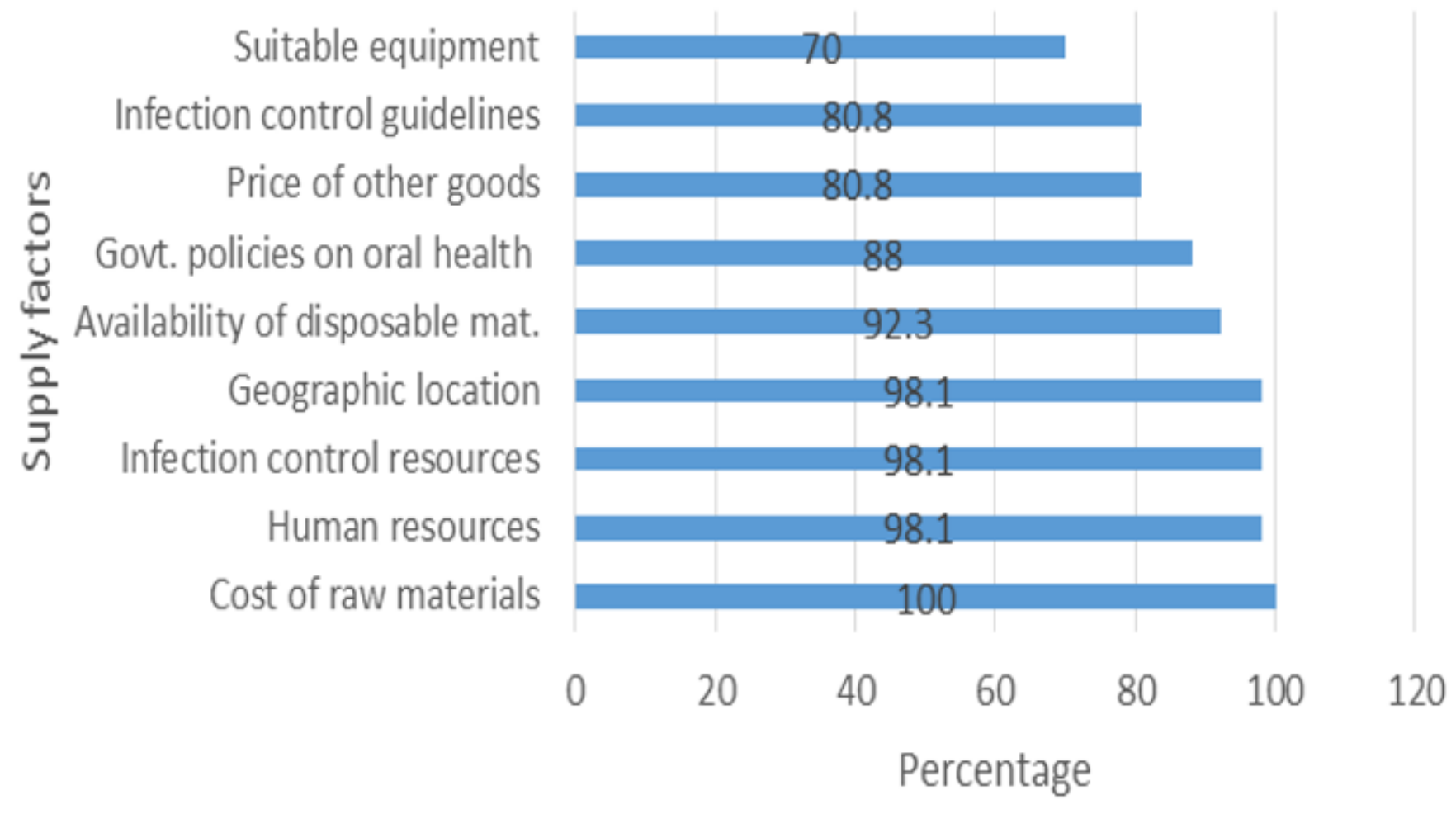

Figure 2

Factors that determine the provision of dental caries services

\section{Supplementary Files}

This is a list of supplementary files associated with this preprint. Click to download.

- STROBEStatement.docx 